\title{
Health Issues of Women in Old Age: A Literature Review
}

\author{
Manpreet Kaur ${ }^{1}$, Jasbir Kaur ${ }^{2}$
}

\begin{abstract}
India, the largest democracy of the world and second most populous country, is now also emerging as the sixth largest economy in the world. There are around 104 million elderly persons (8.6\%) (Census, 2011) and the number is expected to increase to 296.6 million constituting $20 \%$ of the total population by 2050. The sex ratio of the elderly was 938 women to 1,000 men in 1971 which has increased to 1,033 in 2011 and further projected to increase to 1,060 by 2026 . These changing trends have led to feminization of aging. Further inherent discrimination and neglect experienced by aging women, frequently exaggerated by widowhood and complete dependence on others. On the social front, old women experience isolation/destitution, financial, and emotional insecurity. This further aggravates the health problems among old women. Elderly women in India face different types of health-related issues due to various socioeconomic factors. Studies report that chronic morbidity, poor vision, cataract, blood pressure, back pain/slipped disc, malnutrition, depression, impaired physical performance, and elder abuse were significantly higher amongst women as compared to elderly men. The literature also reveals that women experience difficulty in coping with these health problems due to widowhood, economic dependency, lack of proper food and clothing, fear of the future, lack of caring, and progressive decline in health made coping with health problems difficult. The socioeconomic and health needs of the women are enormous but, unfortunately, the existing, national policies, and programmatic capacities are inadequate and lack gender sensitivity.

Keywords: Elderly women, Feminization of aging, Health disparities.

AMEl's Current Trends in Diagnosis \& Treatment (2019): 10.5005/jp-journals-10055-0065
\end{abstract}

\section{INTRODUCTION}

The human life span is considered as hundred years on an average as per Indian traditional culture. The ancient Dharmasastra divided the human life span into four "ashramas" of life stages. The first, "brahmacarya", "grihsta" "vanaprastha," and "samnyasa" or asceticism. The last two stages were considered as more mature and aging man who would gradually give up his worldly pursuits, move away from the mundane routine of the householder, and turn inward in search of spiritual growth. Though this scheme of a man's life did not have any mention about a women's life, it was assumed that a wife would follow her husband faithfully in his move through different stages. On social front, a transition from adulthood to old age is assumed as when children got married and they had grandchildren, regardless of their chronological age and especially for women it is often correlated as attainment of menopause. ${ }^{1}$

Generally, in terms of chronological age, aging is defined with a cutoff age of 60 or 65 years. This definition is partly due to the fact that retirement age ( 58 for government jobs) is also similar to this cutoff age. However, in many developing countries including India, chronological age carries very little relevance to retirement as majority of the elderly are engaged in informal sector with no specific retirement age. Therefore, the meaning of aging is more relevant in the context of society, where getting old means getting new roles or loss of certain roles in relation to physical decline. ${ }^{2}$

As depicted in Figure 1, India has around 104 million elderly persons $(8.6 \%$, census, 2011) and the number is expected to increase to 296.6 million constituting $19 \%$ of the total population by 2050 (United Nations, 2017). ${ }^{3}$ By the end of the century, the elderly will constitute nearly $35 \%$ of the total population in the country. Summary figures reflect the unevenness and complexities of the demographic transition within India across different Indian states. Projected estimates of population structure in 2025 for North India retain a "pyramidal" shape, while for south India, the share of the elderly
1Department of Community Health Nursing, Sri Guru Ram Das College of Nursing, Sri Guru Ram Das Institute of Medical Sciences and Research, Sri Guru Ram Das University of Health Sciences, Amritsar, Punjab, India ${ }^{2}$ Department of Mental Health Nursing, Maharishi Markandeshwar College of Nursing, Maharishi Markandeshwar University, Ambala, Haryana, India

Corresponding Author: Manpreet Kaur, Department of Community Health Nursing, Sri Guru Ram Das College of Nursing, Sri Guru Ram Das Institute of Medical Sciences and Research, Sri Guru Ram Das University of Health Sciences, Amritsar, Punjab, India, Phone: +91 7009001436, e-mail: manpreet_arora001@rediffmail.comm

How to cite this article: Kaur M, Kaur J. Health Issues of Women in Old Age: A Literature Review. AMEl's Curr Trends Diagn Treat 2019;3(1):27-32. Source of support: Nil

Conflict of interest: None

population is expected to expand considerably. Linear growth in the population of the elderly is expected in the next 100 years, with steeper gradients of increase in central and east India and leveling of absolute numbers of elderly in the north, south, west, and northeast (Aliyar and Rajan, ${ }^{4}$ Dey et al. ${ }^{5}$ ). Majority of elderly live in rural areas and there is an increasing proportion of old-oldest age category along with the characteristic of feminization of aging. Elderly population analysis shows that in upper age groups, population of older women is increasing remarkably. At the age of $65,70,75$, and 80 , there are 1,310, $1,590,1,758$, and 1,980 elderly women, respectively, per 1,000 elderly men (Fig. 2). The sex ratio of the elderly has increased from 938 women to 1,000 men in 1971 to 1,033 in 2011 and is projected to increase to 1,060 by 2026 . As the data indicate increase in feminization of aging, which often gets further challenged by widowhood and complete dependence on others. Loss of spouse in old age adds significant vulnerability in later years especially for women. Nearly three out of five single older women are very poor and about two-thirds of them are completely economically dependent upon significant others. ${ }^{6}$ 


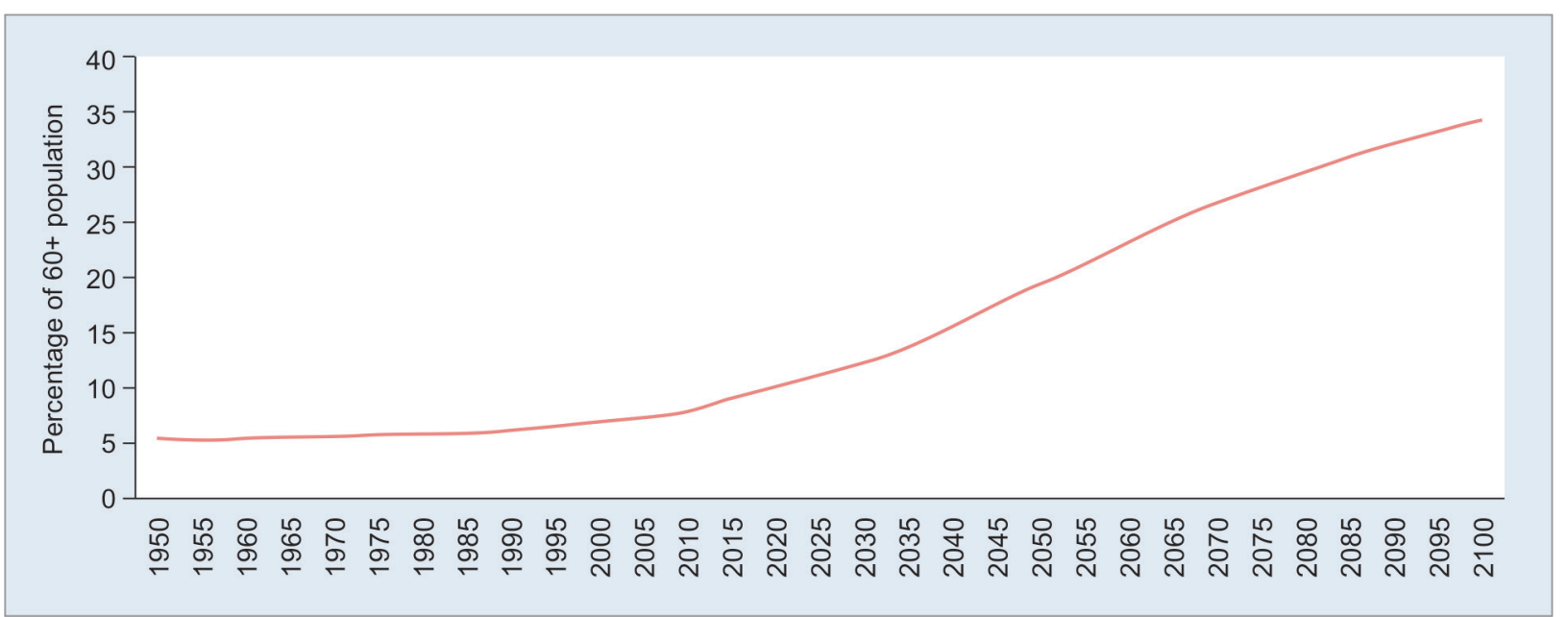

Fig. 1: Estimated percentage of 60-plus persons in total population, India, 1950-2100. Source: Analysis by Agewell Research \& Advocacy Centre based on Census of India's data ${ }^{7}$

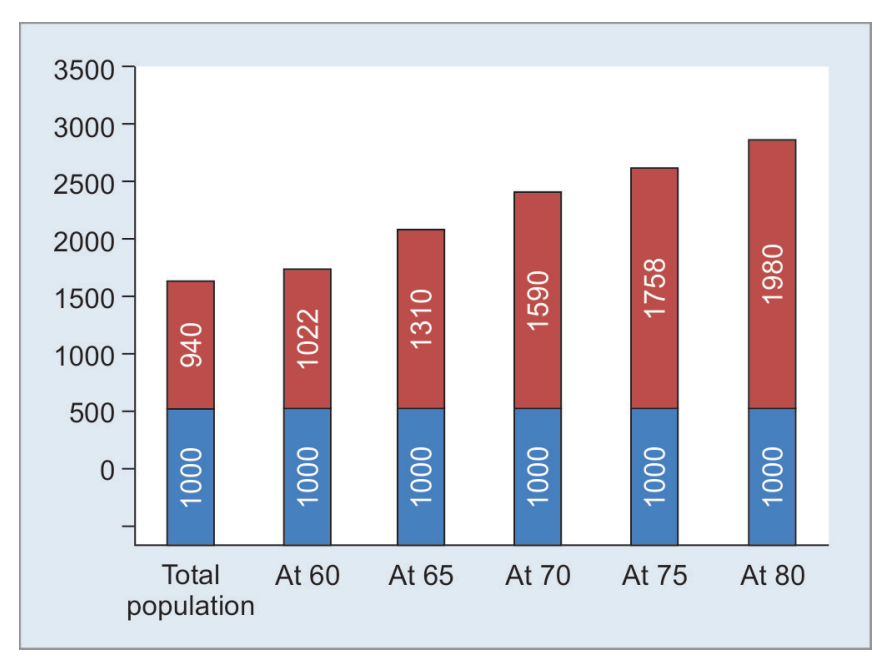

Fig. 2: Male-female ratio total population and above 60 years in India

The literature has hardly any mention of women till few decades ago, when average age of women in India was less than 60. But now recently because of increased life expectancy and higher percentage of elderly women in Indian elderly population, the phenomenon has gained attention amongst social researchers. The traditional family structures, which were meant to care for the elderly, are shrinking as urbanization grows and resources become scarce in rural areas. Within this cohort of the elderly, women face many more problems like marginalization and isolation due to gender discrimination. They are often treated as unpaid caregivers to their grandchildren and made to do household chores in return for a roof over their heads. In many Indian households, women are not encouraged to be decision-makers even in their productive years (Panicker ${ }^{7}$ ). The problems experienced by elderly women cannot be ignored now, as these are posing a major social development challenge in our society. ${ }^{6}$

\section{Major Concerns of Old Women}

Agewell Foundation has delineated following major concerns of old women in India. ${ }^{8}$

\section{Destitution/Alienation/Isolation}

As socioeconomic scenario of the country is changing very rapidly along with fast paced modern lifestyle and rapid urbanization, younger generations hardy interact with their elderly family members. Popularity of nuclear family system has virtually crushed strong traditional bond between grandchildren and grandparents.

\section{Social Insecurity}

As the family structure has dissolved gradually, older women, who live in cities, are more prone to social alienation in comparison to their counterparts living in villages. This lack of social protection has forced elder women to lead a life full of distress.

\section{Financial Insecurity}

As the life expectancy has increased, financial insecurity among women has also emerged as another important concern which has direct implication for decisions related to health. Majority of the women are not entitled their right on ancestral property of money and of few those have are not allowed to make financial decisions due to social traditions and beliefs.

\section{Medical Problems}

Older women usually suffer from chronic health problems as often symptoms or physical complaints go unnoticed or just correlated as age-related changes. Their treatment-seeking behavior also gets delayed due to negligence, lack of awareness, financial support, and religious mindset of women.

\section{Health Concerns of Old Woman}

Santosh has conceptualized the term Geriatric syndrome, which depicts physiological decline brought by aging $^{9}$ (Flowchart 1). After infants and children, old people are most vulnerable to morbidity and mortality as health. While the debilitating effects of old age cannot be avoided, risks can be minimized through careful planning and prevention beginning from middle age (Patwardhan ${ }^{10}$ ). Advances in medical technology over the past years have promoted longevity but not good health.

As the pattern of illness among elderly is quite different from that of the adults, therefore the basic philosophy approach and mode of treatment to the illness of the old also need to be different. 
Flowchart 1: Pathophysiology of health issues in geriatrics

\begin{tabular}{|c|c|c|c|c|c|c|c|c|}
\hline \multicolumn{9}{|c|}{ Aging } \\
\hline \multicolumn{2}{|c|}{$\begin{array}{l}\text { Changes in body } \\
\text { composition }\end{array}$} & \multicolumn{2}{|c|}{$\begin{array}{l}\text { Discrepancy in energy } \\
\text { production/utilization }\end{array}$} & \multicolumn{2}{|c|}{$\begin{array}{l}\text { Homeostatic } \\
\text { dysregulation }\end{array}$} & & \multicolumn{2}{|c|}{ Neurodegeneration } \\
\hline \multicolumn{9}{|c|}{ Frailty } \\
\hline \multicolumn{9}{|c|}{ Geriatric syndromes } \\
\hline $\begin{array}{l}\text { Anorexia/ } \\
\text { malnutrition }\end{array}$ & $\begin{array}{l}\text { Gait disorders/ } \\
\text { falls }\end{array}$ & Disability & $\begin{array}{l}\text { Disease susceptibility/ } \\
\text { comorbidity }\end{array}$ & $\begin{array}{c}\text { Urinary } \\
\text { incontinence }\end{array}$ & $\begin{array}{l}\text { Decubitus } \\
\text { ulcers }\end{array}$ & $\begin{array}{l}\text { Sleep } \\
\text { disorder }\end{array}$ & Delirium & $\begin{array}{l}\text { Cognition } \\
\text { impairment }\end{array}$ \\
\hline
\end{tabular}

The National Opinion Research Center defined illness as "any condition, i.e., any disease, impairment, symptom, or a group of related symptom, which was reported by the aged as having bothered them" (Soodan ${ }^{1}$ ). The aged have different and usually multifaceted health problems. Generally, they have complaints toward muscular pain, eye and hearing impairment, and respiratory problem. Some major diseases like blood pressure, arthritis, and asthma are seen to be more pronounced during the old age. The national sample survey data show that $7.4 \%$ in rural and $7.9 \%$ elderly in urban areas were suffering from one or the other chronic diseases (Chaturbhuj $\left.{ }^{11}\right)$.

The varied data on health problems of elderly are available. In 1996 , the number of hypertensive among the elderly population was nearly 9 million. The prevalence rate of coronary heart disease among the urban population was nearly three times higher than rural population. An estimated 5 million were diabetic and the prevalence rates were about 177 for urban and 35 per 1,000 for rural elderly people. Crude prevalence rate of strokes is estimated to be about 200 per 1,00,000 persons. Older persons surviving through peak years of stroke (55-65 years) with varying degrees of disability are already a major medical problem (Dalal ${ }^{12}$ ).

The pattern of disease among Indian and Western elderly population is quite similar but not the cause of death. Ramachandran and Radhika, in their comparative study on elderly women in India and Japan found that elderly women in India face different types of health-related issues due to various socioeconomic factors. Lack of health awareness among the elderly and financial constraints are the major contributory factors for the poor health of the elderly in India. ${ }^{13}$

The health profile of elderly women is more compromised as compared to elderly male. The differences could lie in biological, social, and cultural factors. Various studies based on primary and secondary data have analyzed various health and health-related issues faced by elderly people especially elderly women. Singh and Yesudian in their analysis using NSSO 2004 and Census 2001 suggest that the physical mobility is high among elderly men than elderly women in both urban and rural areas. The health condition and physical mobility is poorer for urban elderly women than rural elderly women. Rural elderly women perceive that they are in poor health condition than their urban counterparts. ${ }^{14}$

Hiremath studied the health status of elderly women in rural Karnataka. The findings revealed that elderly women were depicted with hypertension (78.65\%), osteoarthritis $(73.03 \%)$, diabetes (66.29\%), and bronchial asthma (77.52\%). Others included cataract $(65.16 \%)$, and anemia and skin problems $(61.79 \%)$.
It was also reported that most of the respondents had more than one health problem. The author concluded that main facts being that, the older women as they age, often reflect the cumulative impact of poor diets, lack of good food and safe drinking water, a gender-based division of domestic tasks, and environment hazards, etc. ${ }^{15}$

In another study on elderly by Audinarayana in Tamil Nadu, marked genderwise differentials in health status of the elderly were documented. Chronic morbidity due to poor vision, cataract, blood pressure, and back pain/slipped disc was significantly higher amongst women as compared to elderly men. Similarly perceived health status of elderly men was significantly better $(p<0.001)$ "healthy" than those of elderly women. ${ }^{16}$

Lena et al. in their study on health and social problems of the elderly in Karnataka depicted that $60.3 \%$ of the elderly women were hypertensive, $57.9 \%$ had osteoarthritis, more pronounced as compared to men. re than half, $55.8 \%$ of the women felt that they are burden on their family, and unhappiness with their life was also reported by more of the women as compared to elderly men. Women also had poor perception regarding economic and social security as compared to men. ${ }^{17}$

Mehrotra and Batish conducted a study to assess the problems among randomly selected elderly females of Ludhiana, Punjab. The major physical problems reported were reduced vision (81.25\%), dental decay (77.5\%), and body weakness and pain (68.75\%), whereas major economic problems were related to medical expenditure (85\%), lack of freedom on spending (77.5\%), and reduced personal income (65\%). Amongst socio-psychological problems, stress and strain was the prominent problem (85\%) followed by declining authority (77.5\%), loneliness (72.5\%), and feeling of neglect (65\%). The relationship between age and physical problems of elderly females was found to be non-significant (2.824), whereas it was significant with respect to social-psychological problems (13.98)..$^{18}$

Kaur et al. in their study on physique of rural and urban Jat Sikh women studied the change in weight with aging. The study findings revealed that there was decrease in mean weight of Jat Sikh women from $66.94 \mathrm{~kg}$ at age $61-65$ years to $49.68 \mathrm{~kg}$ at $81+$ years. Another interesting finding of the study was in relation to change in weight as depicted by comparison with another study conducted by Singal and Sidhu. The results depicted that mean weight has increased significantly in all age groups as mean weight of Jat Sikh women was $51.37 \mathrm{~kg}$ in 1981 and $66.94 \mathrm{~kg}$ in 2004. The results conclude that such an increase in weight due to rapid change in lifestyle increases their vulnerability to chronic diseases. ${ }^{19}$ 
It is also argued that economic security, good health, and adequate housing, in general, constitute fundamentals for aging with dignity. However, the impact of gender differences and inequalities limits women to access aging with dignity, thus hitting them hardest in old age. Due to their secondary status in society, women remain socially, economically, and medically marginalized. As most women outlive their husbands, they will be living a widowed status for longer years especially in India because wives are usually younger than husbands (by 5-10 years or more), and the remarriage rates among them is low (Gulati and Rajan; ${ }^{20}$ United Nations, ${ }^{21}$ Gubhaju ${ }^{22}$ ).

The high age dependency of women who are usually unemployed, illiterate, and poor poses a big challenge for their survival especially in India. At the same time, their longevity compared to men makes them end up to a great numbers living without the spouse to take care of them (Grewal et al. ${ }^{23}$ ). Studies have shown that there is likelihood of widows living alone, living in poverty, and living with poorer health. As old widowed women, they would have higher burden of disease to that of older widowers demographically (Judd; ${ }^{24} \mathrm{Nagla}^{25}$ Agrawal and Keshri ${ }^{26}$ ). Old widows ignore their health status and consider it as being normal until they suffer from serious medical ailment. At the time of health emergency, it is the family which still determines the health situation of widows in terms of support and care. However, widows try to remain productive to the household (despite health issues) because it entails their social status in the family (Bharati and Mahapatro ${ }^{27}$ ).

In a study on 150 aged widows in rural areas of Hissar district, Haryana, Sushma and Darshan noticed that most of them were suffering from multiple ailments. Around $45 \%$ widows had asthma; $90 \%$ had general weakness, problems of eyesight, teeth, and forgetfulness; $31 \%$ had mental anxiety; sand $21 \%$ had heart diseases and various other chronic illnesses. Consulting a physician was done in three-fourth cases in serious conditions, and 16\% always consulted the doctor while others never consulted a doctor. ${ }^{28}$

In large epidemiological studies, women have shown a preponderance to mental health issues as compared to men and this may be also due to predisposed biological and social risk factors (Rajan et al., ${ }^{29}$ Nygren, et al. ${ }^{30}$ Women in old age are more prone to social insecurity, health problems, and greater emotional/ financial insecurities (Patel et al., ${ }^{31}$ Singh, Pradhan ${ }^{32}$ ). Lower levels of education are shown to be associated with higher rates of dementia and consequently more among females (Chandra et al. ${ }^{33}$ ). Female elderly compared to their male counterparts suffered from functional impairments like malnutrition, depression, impaired physical performance, and urinary incontinence more significantly (Shan et al. ${ }^{34}$ ). Marital status and economic dependence play a significant role in determining morbidity amongst elderly women $\left(\right.$ Dilip $\left.^{35}\right)$. The authors concluded that with increasing age, diseases are more likely to increase with widowhood, divorce, and economic dependence. Similarly, in another study of elderly rural females in Rajasthan, Sharma found that widowhood, economic dependency, lack of proper food and clothing, fear of the future, lack of caring, and progressive decline in health made coping with health problems difficult. Elderly widows from poor socioeconomic families had very poor health status. The factors which influenced positive aging were reported as adequate financial status, good physical and mental health, active participation in leisure activities, continuation of hobbies, maintenance of daily schedule, retaining social networks, and assuming social roles. ${ }^{36}$
Joshi et al. studied morbidity profile and its relationship with disability and psychological distress among elderly people in Northern India. The findings of the study reveal that it was more in females (94.1\%) as compared to $81.3 \%$ of the males. Similar trend was noticed in both rural and urban area. The physician diagnosed morbidities (7-9 in number) were observed among $26.4 \%$ of the women. The most common observed morbidities among women were anemia, dental problems, hypertension, cataract, and osteoarthritis. Psychological distress was reported by $66.6 \%$ of the urban women and $82.3 \%$ of the rural women. Fractures after fall were also reported more frequently among females (26.4\%) compared to males $(16 \%){ }^{37}$

In a study to elicit morbidity and healthcare utilization by elderly women in an urban slum in Chennai, Gayathri revealed that $40.5 \%$ of ailments of the elderly women were medically untreated. The most important reasons for not seeking care were financial problems, the perception of ailments as not serious. This information is indicative of inaccessible healthcare which increases financial burden on elderly women and absence of social security and health insurance. The author concluded that social policy of developing countries like India underplays the healthcare requirements of elderly women. ${ }^{38}$

Mental health of the elderly is another domain in acknowledging the overall health situation in this age group. Sharma in his study on mental health issues of elderly reveals that elderly women are affected more by dementia, depression, and psychosomatic disorders than their male counterparts. ${ }^{39}$

Kaur et al. studied psychosocial stresses in rural and urban Jat Sikh women with special reference to senescence. The researchers revealed that the stress score of rural married women was more than that in urban. The stress score of whole life was the highest for rural widows. ${ }^{19}$

Roy and Chaudhuri reported influence of socioeconomic status, wealth, and financial empowerment on gender differences in health and healthcare utilization in later life among nationally representative 34,086 older men and women. The findings of the study revealed that older women had worse self-rated health, higher prevalence of disabilities, marginally lower chronic conditions, and lower healthcare utilization than men. Further statistical analysis revealed that upon controlling for economic independence, gender differentials disappear or are reversed, with older women having equal or better health than otherwise similar men. The study findings concluded that financial empowerment might enable older women the health advantage reflected in developed societies by enhancing a woman's ability to undertake primary and secondary prevention during their life course. ${ }^{40}$

Rastogi et al. carried out a cross-sectional study on major health problems of the geriatric in Ahmadabad. The study findings revealed that among females memory disturbance (42.8\%) and depression (28.6\%) are more as compared to males. ${ }^{41}$ Mathur examined the predictors of depression among 400 aging women $(n=400)$ in Meerut. The results showed that the level of economic status followed by education and social support are the prime factors contributing to depression in aged women. ${ }^{42}$ Alam et al., in his study on mental health of elderly in Raipur reported higher prevalence of mental health issues such as anxiety $(p 0.02)$ and insomnia ( $p$ 0.02) among women as compared to men. ${ }^{43}$

Beyond physical, mental, and social problems unique to elderly women, another challenge in today's scenario is elder abuse. Here also vulnerability of women is more owing to significant financial, social dependency of women upon their families. Chokkanathan and 
Lee examined the extent and correlated elder mistreatment among 400 community dwelling older adults in Chennai. The prevalence rate of mistreatment was $14 \%$. Chronic verbal abuse was the most commonly reported abuse followed by financial abuse and the rate of physical abuse, and neglect was almost same. Multiple type of mistreatment was reported by almost half of the elderly. As compared to men, a significantly greater number of women experienced verbal and physical abuse as well as neglect, except for the financial abuse. Adult children, daughters-in-law, spouses, and sons-in-law were the most frequent abusers. Logistic regression analysis revealed gender, social support, and subjective rating of physical health as significant factors associated with abuse. ${ }^{44}$ Similarly a study by Sebastian and Sekher in Kerala revealed that for females, the chances of being abused in comparison to males were almost $41 \%$ higher in case of mild abuse and 3.75 times significantly higher in case of severe abuse. The likelihood of mild abuse was $42 \%$ higher among the widows/divorced/single elderly and $14 \%$ higher for severe abuse than those who lived with their spouses. ${ }^{45}$

Although population aging is a reflection of social development and public health. However, if aging is to be a positive experience, it must be accompanied by improvements in the quality of life (QOL) of those who have reached or are reaching old age (Suchitra ${ }^{46}$ ). Elderly women in India are vulnerable to various hazards even from their infancy. Old age is an accumulation of all these hazards and disadvantages that reduces the QOL. Rajasi et al. conducted a study to assess the QOL and sociodemographic factors affecting QOL of elderly women residing in a community setting in South Kerala. The researchers used World Health Organization QOL (WHOQOL-BREF) scale to study QOL among elderly. Data were collected from 160 elderly women. Very few (2.5\%) study participants were having "very good" QOL. 38.8 had "good," 43.1\% had "poor," and 15.6\% had "very poor" QOL. QOL was least in the psychological domain followed by physical and health-related, social, and environmental domains. Logistic regression revealed age above 70 years, nonpossession of property, neglecting attitude by family (adjusted OR-6.9), and absence of visit by friends and relatives (adjusted OR-9.9) as risk factors, whereas residing in the urban area as a protective factor (adjusted OR-0.1) for poor QOL. ${ }^{47} \mathrm{~A}$ similar study conducted by Joshi et al. among the elderly population in Northern India showed that psychological wellbeing, physical, and social support almost had identical influences on QOL. ${ }^{48}$ Physical ill health among old women affecting their mental status and altogether reducing their quality of life critically (Nair et al. ${ }^{49}$ ).

Another unique problem faced by elderly women is related to their sexual health which is considered as taboo in many cultures including India. The research has brought to light several serious problems. For example, older women are at increased risk of being victims of sexual violence because of their socioeconomic dependency and, in some settings, because of gender-based inequities. Sexual harassment and violence often take place within the home and widows are particularly vulnerable to these forms of abuse. Post-menopausal changes among elderly women to the lining of the vagina can reduce innate protective mechanisms against infection. Older women, who already have a chronic or acute pelvic infection and compromised immunity, have increased vulnerability to additional infectious diseases including HIV. ${ }^{50}$

It is clear from the above review of above studies that issues faced by elderly in general and elderly women in particular are affected by many interwoven aspects of their social and physical environment. The socioeconomic and health needs of the elderly are huge and multifactorial but, unfortunately, the financial resources, policies, and programmatic capacities available to meet them are inadequate and lack gender sensitivity. Existing social policies and programs should recognize the social, emotional, and healthcare requirements of older women. An imperative tool is to encourage community participation of elderly women to reduce social isolation and promote integration in social and economic processes resulting in improvement of their QOL (Gupta $\left.{ }^{51}\right)$.

Ultimately, India will win if it recognizes for gender sensitivity and especially taking care its women and mothers.

\section{Conclusion}

In India, the number of elderly is growing at an unprecedented rate with increasing visible phenomenon of feminization in aging. This subsequently leads to more of physical, psychological problems, and discrimination on economic and social front. Old women experience varied health problems which are further exacerbated by widowhood, economic dependency, and lack of perception about these problems amongst them and significant others. Present national policies and programs are inadequate and lack gender sensitivity. The need of the hour is to understand the complex nature of problems faced by elderly females and take appropriate action to resolve these.

\section{References}

1. Soodan KS. Ageing in India. Kolkata: Minerva Association Pvt. Ltd; 1975.

2. Prakash IJ. Ageing in India. Geneva: World Health Organization; 1999.

3. India Ageing Repot 2015. https://india.unfpa.org/sites/default/files/ pub-pdf/IndiaAgeingReport 2017.pdf.

4. Aliyar S, Rajan SI. Population projections for India, 2001-2101. Thiruvananthapuram: Centre for Development Studies; 2008.

5. Dey S, Nambiar D, Lakshmi JK, et al. Health of the elderly in India: challenges of access and affordability. In: Smith JP, Majmundar M, ed., Aging in Asia: Findings From New and Emerging Data Initiatives. Washington (DC): National Academics Press; 2012.

6. Perappadan BS, (2016, August 16). Situation worse for old women in India. Retrieved from https://www.thehindu.com/news/ cities/Delhi/\%E2\%80\%98Situation-worse-for-old-women-inIndia\%E2\%80\%99/article14572641.ece.

7. Panicker L. India is no country for older women. Hindustan Times; 2018.

8. Older women in India-A Note by Agewell Foundation-India. Retrieved from www.agewellfoundation.org.

9. Salagre Santosh B, Health Issues in geriatrics. Retrieved from www. apiindia.org/medicine_update_2013/chap177.pdf.

10. Patwardhan B, Gokhale S. Longevity Phenomenon in India: Emerging Issues and Responses. A theme discussion paper for UNESCAP Expert Group Meeting on Assessing Regional Implementation of Commitments from the World Summit for Social Development, Bangkok, Thailand; 2013.

11. Chaturbhuj S. Problems of Ageing among the Indian Tribes. New Delhi: Surup \& Sons; 1998.

12. Dalal PM. Strokes in the elderly: prevalence, risk factors and the strategies for prevention. Indian J Med Res 1997;106:352.

13. Ramachandran R, Radhika R. Problems of elderly women in India and Japan. Indian J Gerontology 2006;20:219-234.

14. Singh DP, Yesudian P. After age 60 in India-a glimpse through census and NSSO. Indian J Soc Work 2007;68(4):545-560.

15. Hiremath SS. The health status of rural elderly women in India: a case study. Int J Criminol Sociol Theory 2012;5(3):960-963.

16. Audinarayana N, Sheela J, Kavitha N. Are the elderly women the most deprived among the deprived? A micro level investigation in rural 
Tamil Nadu. In: Aging: Indian Perspectives. Tharabhai L, ed. New Delhi: Decent Books; 2002. pp. 247-262.

17. Lena A, Ashok K, Padma M, et al. Health and social problems of the elderly: a cross-sectional study in Udupi Taluk, Karnataka. Indian J Community Medicine: Off Publ Indian Assoc Preventive \& Soc Med 2009;34(2):131-134. DOI: 10.4103/0970-0218.51236.

18. Mehrotra N, Batish S. Assessment of problems among elderly females of Ludhaiana city. J Hum Ecol 2009;28(3):213-216. DOI: 10.1080/09709274.2009.11906242.

19. Kaur J, Singal P, Sidhu LS. Physique and psychosocial stresses in rural and urabn Jat Sikh women with special reference to senescence. Unpublished PhD Thesis. Patiala: Punjabi University; 2004.

20. Gulati L, Rajan LS. The added years: elderly in India and Kerala. Economic Political Wkly 1999;34(44):WS46-WS51.

21. United Nations. World population ageing: 1950-2050. Department of Economic and Social Affairs. New York: Population Division; 2007

22. Gubhaju B. Fertility transition and population ageing in the Asian and pacific region. Asia-Pacific Population Journal 2008;23(2):55-80.

23. Grewal GS, Kishore J, Charu. Age-friendly primary healthcare services: emerging need in India. J Indian Acad Geriatrics 2017;13(1):27-31.

24. Judd K. Gender dimensions of ageing, Women 2000. United Nations Division for the Advancement of Women (UNDAW), Department of Economic and Social Affairs. Retrieved from http://www.un.org/ womenwatch/daw/public/ageing-final.pdf.

25. Nagla BK. Ageing and health: a sociological analysis. In: Sharma ML, Dak TM, ed. Ageing in India: challenge for the society. Delhi: Ajanta Publications; 1987.

26. Agrawal G, Keshri K. Morbidity patterns and healthcare seeking behavior among older widows in India. PLoS One 2014;9(4):e94295. DOI: 10.1371/journal.pone.0094295.

27. Bharati K, Mahapatro SR. Healthcare and ageing: a study of old widows in rural Haryana. Jharkh J Dev Manag Stud 2018;16(3): 7829-7844.

28. Sushma V, Darshan S. Health problems of aged widows in rural Haryana. Ageing Soc 2004; 14.

29. Rajan SI, Sarma PS, Mishra US. Demography of Indian aging, 2001-2051. J Aging Soc Policy 2003;15(2-3):11-30. DOI: 10.1300/ J031v15n02_02.

30. Nygren B, Aléx L, Jonsén E, et al. Resilience, sense of coherence, purpose in life and self-transcendence in relation to perceived physical and mental health among the oldest old. Aging Ment Health 2005;9(4):354-362. DOI: 10.1080/1360500114415.

31. Patel V, Kirkwood BR, Pednekar S, et al. Gender disadvantage and reproductive health risk factors for common mental disorders in women: a community survey in India. Arch Gen Psychiatry 2006;63(4):404-413. DOI: 10.1001/archpsyc.63.4.404.

32. Singh A, Pradhan SK. Menopausal symptoms of postmenopausal women in a rural community of Delhi, India: a cross-sectional study. J Midlife Health 2014;5(2):62-67. DOI: 10.4103/0976-7800. 133989.

33. Chandra V, Ganguli M, Pandav R, et al. Prevalence of Alzheimer's disease and other dementias in rural India: the indo-US study. Neurology 1998;51(4):1000-1008. DOI: 10.1212/WNL. 51.4.1000.
34. Shan SK, Sahu T, Sahani NC, et al. Functional status of the older persons residing in urban slums. Indian J Gerontology 2003;17(3-4):398-407.

35. Dilip TR. The burden of III health among elderly in Kerala. Man India 2003;83(1-2):195-205.

36. Sharma KL. Health status and care giver of elderly in Rajasthan villages. Indian J Gerontology 2003;17(1 \& 2):401-410.

37. Joshi K, Kumar R, Avasthi A. Morbidity profile and its relationship with disability and psychological distress among elderly people in Northern India. Int J Epidemiol 2003;32(6):978-987. DOI: 10.1093/ije/ dyg204.

38. Gayathri B. Access to healthcare among poor elderly women in India: how far do policies respond to women's realities? Gend Dev 2009;17(3):481-491. DOI: 10.1080/13552070903298543.

39. Sharma KL. Dimensions of Ageing: Indian Studies. Jaipur: Rawat Publications; 2009.

40. Roy K, Chaudhuri A. Influence of socioeconomic status, wealth and financial empowerment on gender differences in health and healthcare utilization in later life: evidence from India. Soc Science \& Med 2008;66(9):1951-1962. DOI: 10.1016/j.socscimed.2008.01.015.

41. Rastogi S, Gupta SR, Lala MK. A cross-sectional study done in geriatric age group people living under field practice areas of BJMC Ahmedabad to assess their major health problems and its impact on their living. Int J Health Sci Res (IJHSR) 2014;4(7):56-61.

42. Mathur M. Depression and life style in Indian ageing women. J Indian Acad Appl Psychol 2009;35(1):73-77.

43. Alam MN, Singh SP, Gupta VS, et al. A study on mental health status and its determinants in elderly people of Raipur city, Chhattisgarh, India. Int J Community Med Public Health 2016;3:2982-2986. DOI: 10.18203/2394-6040.ijcmph20163499.

44. Chokkanathan S, Lee AE. Elder mistreatment in urban India: a community based study. J Elder Abuse \& Negl 2006;17(2):45-61. DOI: 10.1300/j084v17n02_03.

45. Sebastian D, Sekher TV. Abuse and neglect of elderly in India families: findings of elder absue screening test in Kerala. J Inian Acad Geriatrics 2010;6(2):54-60.

46. Suchitra ET. Assessment of quality of life among elderly population of Yeroor Panchayath in Kollam district. MDThesis. Thiruvananthapuram, India: Government Medical College; 2008.

47. Rajasi RS, Mathew T, Nujum ZT. Quality of life and sociodemographic factors associated with poor quality of life in elderly women in Thiruvananthapuram, Kerala. Indian J Public Health 2016;60(3): 210-215. DOI: 10.4103/0019-557X.189016.

48. Joshi K, Avasthi A, Kumar R. Health related quality of life (hrqol) among the elderly in northern India. Health Popul Perspect 2003;26(4): $141-153$.

49. Nair SPR, Nair ATS, Varaghese $S$, et al. Morbidity profile and quality of life (QOL) of the beneficiaries of asraya project: a study from Kerala. Int J Med Public Health 2017;7(3):142-146. DOI: 10.5530/ ijmedph.2017.3.29.

50. Lusti-Narasimhan M, Beard JR. Sexual health in older women. Bull World Health Organ 2013;91(9):707-709. DOI: 10.2471/BLT.13.119230.

51. Gupta N. Older women in I ndia: issues and concerns. In: Siva Raju S, Somayajulu UV, Prakasam CP, ed. Aging, health and development. Delhi: B.R. Publishing Corporation; 2013. 